\title{
A Destination's Social Sustainability: Linking Tourism Development to Residents' Quality of Life
}

\author{
Emil Juvan \\ University of Primorska, Faculty \\ of Tourism Studies - Turistica, Slovenia \\ emil.juvan@fts.upr.si
}

Eva Podovšovnik

University of Primorska, Faculty

of Tourism Studies - Turistica, Slovenia

eva.podovsovnik@fts.upr.si

\author{
Miha Lesjak \\ University of Primorska, Faculty \\ of Tourism Studies - Turistica, Slovenia \\ miha.lesjak@fts.upr.si
}

\section{Jasmina Jurgec}

Sava turizem d.d.

jurgec.jasmina@gmail.com

Tourism positively contributes to quality of life (satisfaction with life and emotional wellbeing) of the travelling population, but the question remains how tourism affects quality of life of the host population. Residents' quality of life is an essential aspect of sustainable tourism development and offers an attractive destination attribute for marketing. Research suggests that too much interaction with tourism may reduce hosts' quality of life. Low quality of life, typically demonstrated with a low level of satisfaction with life and poor emotional wellbeing, leads to development of antitourism beliefs and reduces residents' support for tourism. This may impede local policy makers and the tourism industry from developing tourism. High tourism may create income but may also induce public expenses on the account of social costs of tourism. The present study investigates the association of hosts' satisfaction with life with objective (level of tourism development) and subjective (perceived interaction with tourists) levels of tourism development. Results indicate that neither the level of tourism development nor interactions with tourists predict hosts' satisfaction with life and their emotional wellbeing. These findings challenge the existing prevailing assumption that a high level of tourism negatively affects residents' quality of life, by default. A call for empirical evidence on the threshold of quantitative (for example frequency) and qualitative (for example, the nature of the interaction) tourism development is needed to reveal how local authorities can better ensure positive social impacts of tourism on the host population and tourism social sustainability.

Keywords: sustainable tourism, social sustainability, quality of life, residents, destination

(cc)BY-SA https://doi.org/10.26493/2335-4194.14.39-52

\section{Introduction}

Over the last couple of decades, tourism has undergone continuous expansion and diversification to become one of the largest and fastest growing economic sectors in the world (World Tourism Organization,
2017). Tourism is about movement and interaction of people within and away from their everyday environment. This interaction affects how the interacting individuals perceive, feel and think about the social environment; consequently, tourism shapes 'hosts' and 
visitors' lifestyles' (Sharpley, 2014, p. 2). While much of our knowledge about tourism impacts pertains to the aspects of visitors, little is known about the diverse impacts tourism has on the local population. Knowledge of tourism development trends has essential meaning for the continuous prosperity of a destination. Destinations typically embrace existing market demand, attract tourists' attention and support opportunities for tourist visitation. Tourist demand changes over time, but one of the fastest-growing aspects of tourism demand is tourists' awareness of the need to protect the host environment (Buckley, 2011; Peeters et al., 2018). Moreover, tourism sustainability is becoming the paradigm of modern times and with it the interest to preserve and even increase the quality of the host environment (Peeters et al., 2018). Green, healthy and active forms of leisure activities are attracting an increasing number of people. Also, high quality is increasingly present in all aspects of tourism supply, especially in the area of social relations between people involved in tourism (highquality, top-quality tourist service adjusted to the individual) (Vodeb, 2014). Tourist arrivals, tourism infrastructure and tourists' experiences offered change the destination's landscape and inevitably affect residents' lives (Kim et al., 2013; Liang \& Hui, 2016, p. 1). Kubickova et al. (2017, p. 1) argue that 'individuals' perceptions shape the quality of life, which is a multidimensional paradigm with many interpretations of subjective or objective nature.' The impacts of tourism depend on the interaction with tourism and level of tourism development, and hosts may perceive this impact as added or reduced quality of life; the latter may also bring to a serious level residents' irritation over tourism (Doxey, 1975).

Given the tourism trends (World Tourism Organization, 2019) we anticipate that the tourism industry will have a massive expansion in the future, which will bring much appreciated economic benefits to tourist destinations; however, growing tourism also brings a number of negative impacts, including unwanted changes in hosts' lifestyles (Peeters et al., 2018). While investigating the relationship between tourism at various levels of development and residents' quality of life is not new (for example, Doxey, 1975; Murphy, 1985;
Perdue et al. 1990), the generalizability of the relationship remains under-investigated. The present study discusses the social aspects of tourism development, more specifically the perceived quality of life among residents of destinations in different stages of tourism development. It is aimed at contributing to the knowledge about social impacts of tourism for the host residents and within that deriving empirically supported practical implications for the destinations' organizations and policy makers about how to develop tourism, which will increase not only tourist satisfaction with life but also contribute to the life satisfaction of the host population.

\section{Theoretical Background}

Tourism impacts tourists and locals in many ways. A number of different approaches and aspects investigating tourism impacts were adopted in the past; nevertheless, it appears that researchers have 'traditionally assessed the utilitarian attributes of tourism products and services' (Lin et al., 2014, p. 1) in spite of the fact that tourism experiences include a strong affective (i.e. emotional) component (Gnoth, 1997). More attention should therefore be paid to understanding the source of emotions and behaviour, as they play an important role in shaping attitudes not only for tourists, but also for locals. Through a number of consequences which tourism brings to the local community, tourism affects locals' perceptions and actual quality of life. Tourism should focus on the emotional interaction between the host and the guest, as there is still a lack of research into the impact of residents' emotions and consequent impact on their beliefs about and behaviour towards tourism (Ribeiro et al., 2017).

Individuals express their thinking in words, which are based on the emotional experiences at a given time. Thus, the formation of emotions can be influenced by a particular situation, surroundings or events, in connection with the individual's perception. Guests and hosts can build a (strong) contact, allowing them to share experiences, advice, and maybe later develop an emotional attachment. Allport (1961) defines personality 'as a dynamic organization within an individual's psychological and physical systems based on patterns of actions, thoughts, and feelings.' An individual's per- 
sonality is influenced by a number of factors that are shaped by a variety of perceptions. A positive perception of the environment, events and people can lead to positive feelings (including being fulfilled and happy), which is an important factor of quality of life (Dolnicar et al., 2012). Emotions form emotional wellbeing, which is the actual or perceived quality of one's everyday life, typically expressed via feelings of joy, stress, sadness, anger, and fear (Kahneman \& Deaton, 2010) and is one of the seven domains of quality of life (Cummins, 1993). Emotional wellbeing is affected by the level of tourism development (Williams, 1979). More specifically, diverse and rich tourism infrastructure and experiences (for example, events) improve or reduce the emotional wellbeing of residents (Uysal et al., 2012). It is suggested that provision of tourist attractions based on local culture, tradition, lifestyle and history, which are readily available to the local population, will 'foster the emotional well-being of the resident community' (Uysal et al., 2012, p. 440). Different levels of tourism development and interaction with tourists, which are both alleviated with an increased level of tourism development (Butler, 1980), affect one's emotional wellbeing. More specifically, an extended level of interaction with tourists may make local residents irritated. Such interaction may be materialized either through employment in tourism (Pizam, 1978) or simply by living closer to tourist concentration areas (Belisle \& Hoy, 1980). This clearly shows that the level of tourism development and interaction with tourists will have an impact on residents' emotional wellbeing.

Happiness is a personal state derived from positive and negative emotions following one's life events (Sirgy \& Lee, 2006). A number of life events and one's personal or situational characteristics may impact one's feeling of happiness (Rivera et al., 2016, p. 1). Given this view, tourism should be considered as a situation having a different level of impact on an individual's life. For example, at destinations with a larger number of tourists a chance of waiting in queues at a local grocery store or experiencing difficulties with parking a car is by far greater than at destinations with a lower level of tourists; not finding a car park or waiting in long queues will reduce one's feeling of happiness and lower one's perceived satisfaction with life. On the other hand, tourism may also positively affect locals' perception of happiness, given that it is one of the largest start-up trading companies for creating happiness on the planet (Pearce et al., 2011). For example, a well-developed tourism industry provides opportunities for high quality recreation or culinary experiences, which should increase locals' feeling of happiness and satisfaction with life. Hence, no doubt, that tourism industry may be making tourists happy, but the question remains how the tourism industry affects residents' emotional wellbeing and life satisfaction.

Happiness enhances people's personal satisfaction, which contributes to satisfaction with life. Countries with happier residents may benefit more from residents' satisfaction, which may become an intangible destinations asset for managing and marketing with international visitors (Gholipour et al., 2016). Happiness is a major contributor to one's perceived quality of life and a sense of happiness encourages factors of pleasure and achievement (Mohit, 2014). One of the approaches for measuring quality of life is the Gross National Happiness Index aimed at assessing nations' overall happiness (Pratt et al., 2016). Pratt et al. argue that economic indicators do not affect happiness of the residents, but emotional indicators do. More specifically, life satisfaction is a combination of psychological wellbeing, time use, community vitality, cultural diversity, ecological resilience, living standard, health, education, and good governance (Pratt et al., 2016).

Happiness is the basis for quality of life formation and can be perceived differently because of the value of different dimensions within the concept. With the developmental stages, tourism changes from positive to negative and consequently affects a sense of happiness and life satisfaction of local residents. More specifically, tourism has an indirect relationship with quality of life, affecting various economic, socio-cultural and environmental attributes of the host community and thus aspects of locals' life (Rivera et al., 2016), for some in a positive but for others in a negative way (Lee, 2013; Stylidis et al., 2014). Understanding hosts' perceived satisfaction with life is an essential driver 
of tourism development, at the operational and policy level. More specifically, when seeking hosts' support and insights into the directions of tourism development, policy makers must understand how the local population perceives tourism and its impacts on their satisfaction with life. Using such an approach, tourism policy makers and destination organizations have the best possible starting point for preventing negative impacts of tourism and maximizing its benefits, thus achieving greater support for local residents (Prayag et al., 2013; Stylidis et al., 2014). At the operational level, the tourism industry should understand how locals feel about tourism for successful development of socially responsible tourism operations.

Individuals perceive tourism in a subjective way, according to their emotions and living environment. Areas that encompass the everyday life of residents, and acceptance of them, are shaped into a quality of life that is also heavily influenced by different levels of tourism development. More specifically, various levels of tourism development influence levels of residents' interaction with tourists, their involvement and dependence on tourism as well as access to tourismrelated infrastructure and leisure opportunities (Murphy, 1985).

The most adopted approach to study destination tourism development was proposed by Butler (1980). The Tourism Area Life Cycle (TALC) is used in attempts to understand the process of the development of tourist destinations in a wide variety of settings (Butler, 2006). The model originally hypothesized six stages of destinations development based on a number of indicators; for example, number of tourists, visitation growth over certain time, accommodation occupancy rate, number of beds, tourists per capita expenditure and similar (Uran Maravić \& Juvan, 2009). Although the model has been widely adopted and referenced in many academic and professional resources (Ho \& McKercher, 2015) it is assumed that most of the empirical evidence is of limited validity. Nevertheless, the model is still a valid approach in defining the development stage of a tourism destination for various reasons, including policy making, strategic development and even scientific purposes (Ho \& McKercher, 2015). As per the authors' best knowledge, no attempt has been made so far to classify Slovenian tourism destinations using the TALC model; however, a few publications have touched the different stages of tourism development in Slovenia (for example, Uran Maravić \& Juvan, 2009).

This literature review allows concluding that (1) the impact of tourism development plays an important role in the emotional aspects of the host's life satisfaction. Overall, research shows that tourism has a positive and negative impact; (2) not all residents perceive similar impacts of tourism - those who benefit directly from tourism through employment are likely to be better supporters and report higher levels of satisfaction with different aspects of life than residents with no specific connection to tourism; and (3) the level of positive emotions depends on the level of tourism development; predictably people are happier and more satisfied with life in cities with early stages of tourism development (Uysal et al., 2016).

Following the theoretical implications of the relations between different stages of tourism development and the quality of life discussed above, we hypothesize the following:

$\mathrm{H} 1$ Level of tourism development predicts residents' satisfaction with life.

$\mathrm{H} 2$ Interaction with tourists predicts residents' satisfaction with life.

$\mathrm{H} 3$ Level of tourism development predicts residents' emotional wellbeing.

$\mathrm{H} 4$ Interaction with tourists predicts residents' emotional wellbeing.

\section{Methodology}

The quantitative approach was adopted to test the proposed hypotheses. Data was collected via an online survey tool $1 \mathrm{KA}$, using a survey questionnaire. The survey was distributed among survey participants using a snowball sampling technique (for example, participants who completed the survey were asked to recommend participation to their peers) and gatekeepers were typically well-known and networked within observed destinations (for example, local tourist information centres, local societies and social clubs). The survey involved participants living in three dif- 
ferent municipalities in Slovenia, with different levels of tourism development.

The survey measured several aspects of life with the following being an interest of the current study:

- Satisfaction with life (Pratt et al., 2016) was measured using a 5-point Likert-type scale (1 - not satisfied at all, and 5 - completely satisfied) for six different aspects of life: health, life standard, work, family relations, balance between work and free time, and relationships with members of the community. Dependent variable satisfaction with life was factor analysed for further regression analysis with hypothesized predictors. Pearson's correlational coefficients were computed to detect multicollinearity and check for internal validity and Cronbach's Alpha was used to assess the reliability. The results show there are statistically significant (at the 0.05 level) correlations among the pairs of indicators of satisfaction with life, suggesting a high level of internal validity; correlational coefficients $f 0.491$ or lower indicate acceptable multicollinearity. The value of the Cronbach Alpha of 0.739 shows an acceptable reliability (George \& Mallery, 2003).

- Emotional wellbeing (Pratt et al., 2016) was measured for the frequency of experiencing three negative (fear, anxiety, depression) and three positive (calmness, contentment, and pleasure) emotions. Participants were asked to express the frequency of experiencing emotions using four categories of answers (frequently, sometimes, rarely and never). To keep the survey instrument as short as possible and thus avoiding respondent fatigue (Dolnicar et al., 2011), the original set of emotions from Pratt et al. (2016) were reduced to six emotions in total. This procedure was done using a qualitative pre-study involving 23 participants. Participants, randomly intercepted in public areas of researched communities, were asked to list three positive and three negative emotions which they remember experiencing most frequently. The emotions most frequently mentioned by interviewees were included in the quantitative survey.
Table 1 Key Tourism Area Life Cycle Indicators for the Observed Destinations

\begin{tabular}{rrrrrrr}
\hline Year/destination & $(1)$ & $(2)$ & $(3)$ & $(4)$ & $(5)$ \\
\hline 2015 & D 1 & 445392 & 1408790 & 14493 & 25.00 & 10294 \\
& D2 & 169 & 51847 & 909 & 0.51 & 780 \\
& D3 & 4603 & 8113 & 237 & 0.21 & 221 \\
\hline 2016 & D 1 & 480736 & 1507890 & 14446 & 27.00 & 11079 \\
& D2 & 25422 & 51649 & 735 & 0.52 & 786 \\
& D3 & 5065 & 7821 & 212 & 0.24 & 225 \\
\hline 2017 & D 1 & 534874 & 1649251 & 14734 & 30.00 & 12279 \\
& D2 & 28202 & 55558 & 758 & 0.58 & 816.6 \\
& D3 & 5156 & 8499 & 161 & 0.24 & 225.8 \\
\hline \multirow{2}{*}{2017} & D1 & 604592 & 1882383 & - & 34.00 & 13827 \\
& D2 & 30855 & 64096 & - & 0.62 & 846 \\
& D3 & 6563 & 13574 & - & 0.30 & 238 \\
\hline
\end{tabular}

Notes Column headings are as follows: (1) arrivals, (2) overnights, (3) beds, (4) T/R, (5) people per $\mathrm{m}^{2}$.

- Level of tourism development was assessed as an objective measurement of tourism development using the TALC tourism development model, with a number of TALC indicators for three observed destinations. More specifically, following recommendations from Uran Maravić and Juvan (2009), we observed tourist arrivals, number of nights, number of beds, number of tourists per local resident and number of people per square meter of land (see Table 1). Given that no empirical evidence exists on the threshold of different TALC indicators specific for the particular TALC stage it was impossible to determine the actual TALC stage for the observed destinations. However, empirical indicators of tourism development allowed the arbitrary decision to split the three communities into two extremely different TALC stages: the high and low level of tourism development. The destination with high TALC is in the later stages of tourism development, and the destination with low TALC is in the earlier stages of tourism development. While the selected dimensions of tourism development are not exhaustive, they do indicate the level of tourism development (e.g. Buttler, 1980) and may 
affect residents' emotional wellbeing and satisfaction with life (Pratt et al., 2016).

- Interaction with tourists was measured as a subjective and objective measurement. Subjectively, the interaction with tourists was assessed by asking participants about the perceived extent of their interaction with tourists in the last 2 years. Responses were captured on a numerical scale with endpoints labelled o - no interaction with tourists at all and $100-$ a lot of interaction with tourists. Respondents from high TALC ( $\mathrm{M}=$ $76.87, \mathrm{SD}=25.06)$ report significantly $(t(546)=$ -14.352, $p<0.001$ ) higher levels of interaction with tourists than their counterparts from low TALC $(M=44.05, S D=28.50)$. Objectively, this concept was measured by asking respondents whether or not they work in the tourism industry. Responses were captured with binary categorical measure (yes, no). Significantly more $\left(X^{2}(1)=82.393, p=0.000\right)$ respondents from high TALC work in tourism. Given the aim of the study, to determine the association between the interaction with tourists and satisfaction with life and emotional wellbeing, we limited ourselves to the quantitative dimensions of interaction with tourists as strong factors of hosts' satisfaction with life (Murphy, 1985; Perdue et al., 1990).

- In addition, a number of socio-demographic characteristics were measured using categorical (for example, education was measured with four response options: elementary school or less, vocational or high school education, college or university degree, postgraduate degree) or with ordinal scale (for example, length of living at the destination was measured with the following response options: less than a year, from 1 to 5 years, from 5 to 10 years, more than 10 years).

Overall, 627 valid surveys were completed (see Tables 2 and 3), of which 295 (47\%) are from the destination in a consolidated TALC stage and 332 (53\%) from that in the involvement TALC stage. $71 \%$ of the final sample are female participants and between 16 and 90 years old $(\mathrm{M}=39.53, \mathrm{SD}=14.3)$. The majority $(79 \%)$ of respondents have lived in their respective destina-
Table 2 Sample Characteristics: Categorical Variables

\begin{tabular}{llrr}
\hline Category & Item & $f$ & $f(\%)$ \\
\hline Gender & Male & 145 & 29.4 \\
& Female & 348 & 70.6 \\
\hline Destination & High TALC & 295 & 47.0 \\
& Low TA LC & 332 & 53.0 \\
\hline Highest level & Elementary school or less & 20 & 4.1 \\
of education & Voc. school, high school & 137 & 49.0 \\
& College, university degree & 195 & 40.3 \\
& Postgraduate degree & 32 & 6.6 \\
\hline Working in the & Yes & 102 & 37.9 \\
tourism sector & No & 167 & 62.1 \\
\hline
\end{tabular}

Table 3 Sample Characteristics: Scale Variables

\begin{tabular}{lrrr}
\hline Item & Valid & 496 & 482 \\
\hline$N$ & Missing & 131 & 145 \\
\hline Mean & 39.530 & 3.620 \\
Stdandard deviation & 14.392 & 0.802 \\
Skewness & 0.458 & - \\
Std. error of skewness & & 2.040 \\
Kurtosis & 0.110 & 0.111 \\
Std. error of kurtosis & -0.397 & 2.968 \\
\hline Minimum & 0.219 & 0.222 \\
Maximum & 16 & 1 \\
\hline Notes Column headings are as follows: (1) & 90 & 4 \\
\hline
\end{tabular}

Notes Column headings are as follows: (1) age, (2) length of living at the destination.

tion for more than 10 years. Almost half of respondents (49\%) have completed vocational or a higher level of education, and $40.3 \%$ of participants completed college or a university degree. On average, $(M=59.77$; $\mathrm{SD}=31.5)$ respondents perceive themselves to have a moderate level of interactions with tourists. Research hypotheses were tested using the regression analysis.

\section{Results}

This section provides empirical testing of the research hypotheses, beginning with a descriptive presentation of the key dimensions of satisfaction with life. 
Table 4 Descriptive Statistics on Dimensions of Satisfaction with Life

\begin{tabular}{lrrrrrrr}
\hline TALC & & $(1)$ & $(2)$ & $(3)$ & $(4)$ & $(5)$ & $(6)$ \\
\hline Low & (a) & 3.73 & 3.53 & 3.50 & 3.96 & 3.50 & 3.66 \\
& (b) & 264 & 253 & 251 & 253 & 252 & 253 \\
& (c) & 1.252 & 1.015 & 0.490 & 1.548 & 0.094 & 1.083 \\
& (d) & -1.151 & -0.911 & -0.838 & -1.155 & -0.562 & -0.961 \\
& (e) & 0.061 & 0.054 & 0.062 & 0.059 & 0.060 & 0.057 \\
\hline High & (a) & 3.74 & 3.35 & 3.49 & 4.15 & 3.41 & 3.69 \\
& (b) & 239 & 232 & 231 & 231 & 232 & 232 \\
& (c) & 1.378 & 0.108 & 0.086 & 2.455 & -0.336 & 0.630 \\
& (d) & -1.197 & -0.662 & -0.496 & -1.395 & -0.513 & -0.524 \\
& (e) & 0.065 & 0.064 & 0.064 & 0.060 & 0.071 & 0.051 \\
\hline Total & (a) & 3.74 & 3.44 & 3.50 & 4.05 & 3.45 & 3.67 \\
& (b) & 503 & 485 & 482 & 484 & 484 & 485 \\
& (c) & 1.287 & 0.501 & 0.282 & 1.862 & -0.119 & 1.040 \\
& (d) & -1.170 & -0.794 & -0.674 & -1.250 & -0.550 & -0.816 \\
& (e) & 0.045 & 0.042 & 0.044 & 0.043 & 0.046 & 0.038 \\
\hline
\end{tabular}

Notes Column/row headings are as follows: (1) health, (2) living standard, (3) work, (4) family relations, (5) balance of work and free time, (6) community relations, (a) mean, (b) $N$, (c) kurtosis, (d) skewness, (e) standard error of mean.

\section{Satisfaction with Life}

Results show (see Table 4) that, on average, respondents are satisfied with family relations $(M=4.05$; SD $=0.935)$, health $(M=3.74 ; \mathrm{SD}=1.002)$ and relationships with members of the community $(M=3.67$; SD $=0.847)$. On average, respondents are neither satisfied nor dissatisfied with work $(M=3.5 ; \mathrm{SD}=0.976)$, balance between work and free time $(M=3.45$; SD = 1.021) and life standard $(M=3.44 ; \mathrm{SD}=0.92)$. In all cases, skewness and kurtosis fall in the interval $|-2 ; 2|$, suggesting a distribution close to a normal one. All the indicators of satisfaction with life were kept for further statistical analysis.

In the following, the Pearson's correlational coefficients were computed (see Table 5), in order to detect multicollinearity and check for internal validity. The results show there are statistically significant (at the 0.05 level) correlations among the pairs of indicators of satisfaction with life, suggesting a high level of internal validity. Since the highest correlational coefficient is 0.491 , there is no evidence of multicollinearity.

The Cronbach Alpha coefficient was computed, in order to check for reliability. The value of the Cronbach Alpha is 0.739 , showing a reliable research instrument in the case of satisfaction with life.

Factor analysis with principal axis factoring was conducted to linearly reduce the number of dimensions of satisfaction with life. The computed communalities (see Table 6) have high extraction scores (> $|0.3|$ ) for life standard, work and balance between work and free time. For other indicators the extraction scores fall slightly outside the interval, but communalities support keeping them as indicators of satisfaction with life. The factor analysis (principal axis factoring) suggests a single factor solution with the initial eigenvalue higher than 1 (2.623). The one-factor solution explains $43.722 \%$ of total variance (see Table 7 ). The factor matrix (see Table 8) supports the one-factor solution, since all the factor scores are higher than $|0.3|$, confirming a high importance of the indicator on the factor. The suggested one-factor solution was kept for further statistical analysis.

Research hypotheses $\mathrm{H} 1$ and $\mathrm{H} 2$ were tested using the regression analysis. Results (see Table 9) show no statistically significant association (at the 0.05 level) between TALC and/or number of interactions with tourists and satisfaction with life. The determination coefficient is 0.004 . The regression model is not statistically significant $(F=0.283$; sig. $=0.838)$.

\section{Emotional Wellbeing}

Over half of respondents (see Table 10) often feel calmness $(54.7 \%$ of respondents) and contentment $(58.9 \%$ of respondents), but a third of respondents feel the two emotions only sometimes $35.3 \%$ for calmness and $34.4 \%$ for contentment). $44.7 \%$ of respondents feel pleasure often and $45.1 \%$ of them feel pleasure sometimes. Regarding the negative emotions, the majority feels them rarely (fear $45.6 \%$ of respondents and depression $47.6 \%$ of respondents) or sometimes ( $46.7 \%$ in the case of anxiety). All the indicators of psychological wellbeing were kept for further statistical analysis.

Regression analysis (see Table 11) was performed to test statistically significant relations between the 
Table 5 Pearson's Correlational Coefficients among Indicators of Satisfaction with Life

\begin{tabular}{|c|c|c|c|c|c|c|c|}
\hline Factor & & (1) & (2) & (3) & (4) & (5) & (6) \\
\hline \multirow[t]{3}{*}{ (1) Health } & Pearson correlation & 1 & $0.361^{\star *}$ & $0.374^{\star *}$ & $0.264^{\star *}$ & $0.222^{\star *}$ & $0.290^{* *}$ \\
\hline & Sig. (2-tailed) & & 0.000 & 0.000 & 0.000 & 0.000 & 0.000 \\
\hline & $N$ & 503 & 485 & 481 & 484 & 484 & 485 \\
\hline \multirow[t]{3}{*}{ (2) Living standard } & Pearson correlation & $0.361^{\star *}$ & 1 & $0.491^{\star *}$ & $0.275^{* *}$ & $0.359^{* *}$ & $0.280^{\star *}$ \\
\hline & Sig. (2-tailed) & 0.000 & & 0.000 & 0.000 & 0.000 & 0.000 \\
\hline & $N$ & 485 & 485 & 480 & 481 & 481 & 482 \\
\hline \multirow[t]{3}{*}{ (3) Work } & Pearson correlation & $0.374^{* *}$ & $0.491^{\star *}$ & 1 & $0.277^{\star *}$ & $0.430^{* *}$ & $0.300^{* *}$ \\
\hline & Sig. (2-tailed) & 0.000 & 0.000 & & 0.000 & 0.000 & 0.000 \\
\hline & $N$ & 481 & 480 & 482 & 479 & 480 & 480 \\
\hline \multirow[t]{3}{*}{ (4) Family relations } & Pearson correlation & $0.264^{* *}$ & $0.275^{* *}$ & $0.277^{* *}$ & 1 & $0.249^{\star *}$ & $0.320^{* *}$ \\
\hline & Sig. (2-tailed) & 0.000 & 0.000 & 0.000 & & 0.000 & 0.000 \\
\hline & $N$ & 484 & 481 & 479 & 484 & 482 & 483 \\
\hline \multirow[t]{3}{*}{ (5) Work and free time balance } & Pearson correlation & $0.222^{\star *}$ & $0.359^{\star *}$ & $0.430^{* *}$ & $0.249^{\star *}$ & 1 & $0.332^{* *}$ \\
\hline & Sig. (2-tailed) & 0.000 & 0.000 & 0.000 & 0.000 & & 0.000 \\
\hline & $N$ & 484 & 481 & 480 & 482 & 484 & 484 \\
\hline \multirow[t]{3}{*}{ (6) Community relations } & Pearson correlation & $0.290^{* *}$ & $0.280^{* *}$ & $0.300^{\star *}$ & $0.320^{* *}$ & $0.332^{\star *}$ & 1 \\
\hline & Sig. (2-tailed) & 0.000 & 0.000 & 0.000 & 0.000 & 0.000 & \\
\hline & $N$ & 485 & 482 & 480 & 483 & 484 & 485 \\
\hline
\end{tabular}

Notes $\quad * *$ Sig. $<0.01$.

Table 6 Communalities in Factor Analysis, for Indicators of Satisfaction with Life

\begin{tabular}{lcr}
\hline Factor & Initial & Extrac. \\
\hline Health & 0.220 & 0.281 \\
Living standard & 0.312 & 0.416 \\
Work & 0.359 & 0.491 \\
Family relations & 0.167 & 0.211 \\
Work and free time balance & 0.253 & 0.315 \\
Community relations & 0.208 & 0.261 \\
\hline
\end{tabular}

Notes Extraction method: Principal axis factoring.

level of tourism development and interaction with tourists and emotional wellbeing. Results suggests that tourism development as well as interaction with tourists have no significant relationship with a particular emotion; the percentage of the explained variance is very low (between 0.3 and 2.2). All the regres-
Table 7 Total Variance Explained with Factor Analysis, for Indicators of Satisfaction with Life

\begin{tabular}{|c|c|c|c|c|c|c|}
\hline \multirow[t]{2}{*}{ Factor } & \multicolumn{3}{|c|}{ Initial eigenvalues } & \multicolumn{3}{|c|}{ Extraction sums ${ }^{\star}$} \\
\hline & (1) & (2) & (3) & (1) & (2) & (3) \\
\hline 1 & 2.623 & $43 \cdot 722$ & 43.722 & 1.975 & 32.914 & 32.914 \\
\hline 2 & 0.847 & 14.111 & 57.833 & & & \\
\hline 3 & 0.787 & 13.116 & 70.949 & & & \\
\hline 4 & 0.685 & 11.418 & 82.367 & & & \\
\hline 5 & 0.568 & 9.474 & 91.842 & & & \\
\hline 6 & 0.489 & 8.158 & 100.000 & & & \\
\hline
\end{tabular}

sion models are not statistically significant at the 0.05 level. There is no evidence of any statistically significant impact (at the 0.05 level) of the level of tourism development or interaction with tourists on residents' emotional wellbeing.

Finally, the overall regression model (ENTER meth- 
Table 8 Factor Matrix, for Satisfaction with Life

\begin{tabular}{ll}
\hline Factor & Value \\
\hline Health & 0.530 \\
Living standard & 0.645 \\
Work & 0.700 \\
Family relations & 0.459 \\
Work and free time balance & 0.561 \\
Community relations & 0.511 \\
\hline
\end{tabular}

Notes Extraction method: Principal axis factoring. 1 factor extracted, 6 iterations required.

Table 9 Associations between Satisfaction with Life, Level of Tourism Development and Interaction with Tourists

\begin{tabular}{lrrrrr}
\hline Item & $B$ & $\mathrm{SE}$ & $\beta$ & $t$ & Sig. \\
\hline (Constant) & 0.109 & 0.336 & & 0.324 & 0.746 \\
TALC & 0.014 & 0.144 & 0.008 & 0.097 & 0.923 \\
Work in tourism & 0.039 & 0.146 & 0.022 & 0.265 & 0.791 \\
Interac. with tourists & -0.001 & 0.002 & -0.049 & -0.578 & 0.563 \\
\hline
\end{tabular}

Notes Dependent variable: Satisfaction with life (factor).

od) was computed where Satisfaction with life is used as the dependent variable and other concepts as predictors. The results (see Table 12) show that the regression model explains $25.8 \%$ of the total variance in Satisfaction with life. The model's fit is good ( $F=$ 6.432; sig. < 0.001). Statistically significant (at the 0.05 level) regression coefficients suggest that contentment $(\beta=-0.174$; sig. $=0.03)$, pleasure $(\beta=-0.181$; sig. $=$ $0.019)$ and the highest level of education $(\beta=0.247$; sig. < 0.001) significantly predict satisfaction with life. The local residents that more often feel contentment and pleasure and have a higher level of education are more satisfied with life compared to their counterparts who never feel contentment and pleasure, and have a lower level of education. The hypothesized prediction of tourism development and interaction with tourists indicates no significant direct association with residents' emotional wellbeing or satisfaction with life.

\section{Findings and Conclusion}

Ensuring residents' emotional wellbeing and satisfaction with life is an important indicator of sustainable
Table 10 Descriptive Statistics on Emotional Wellbeing at Destinations with Different Levels of Tourism Development

\begin{tabular}{|c|c|c|c|c|c|}
\hline \multirow[t]{2}{*}{ Emotion } & \multirow[t]{2}{*}{ Item } & & \multicolumn{2}{|c|}{ TALC } & \multirow[t]{2}{*}{ Total } \\
\hline & & & Low & High & \\
\hline \multirow[t]{8}{*}{ Calmness } & Often & (a) & 141 & 144 & 285 \\
\hline & & (b) & 51.1 & 58.8 & 54.7 \\
\hline & Sometimes & (a) & 105 & 79 & 184 \\
\hline & & (b) & 38.0 & 32.2 & 35.3 \\
\hline & Rarely & (a) & 30 & 22 & 52 \\
\hline & & (b) & 10.9 & 9.0 & 10.0 \\
\hline & Total & (a) & 276 & 245 & 521 \\
\hline & & (b) & 100.0 & 100.0 & 100.0 \\
\hline \multirow[t]{10}{*}{ Contentment } & Often & (a) & 158 & 133 & 291 \\
\hline & & (b) & 59.8 & 57.8 & 58.9 \\
\hline & Sometimes & (a) & 89 & 81 & 170 \\
\hline & & (b) & 33.7 & 35.2 & 34.4 \\
\hline & Rarely & (a) & 16 & 16 & 32 \\
\hline & & (b) & 6.1 & 7.0 & 6.5 \\
\hline & Never & (a) & 1 & o & 1 \\
\hline & & (b) & 0.4 & 0.0 & 0.2 \\
\hline & Total & (a) & 264 & 230 & 494 \\
\hline & & (b) & 100.0 & 100.0 & 100.0 \\
\hline \multirow[t]{10}{*}{ Enjoyment } & Often & (a) & 115 & 106 & 221 \\
\hline & & (b) & 44.1 & 45.5 & $44 \cdot 7$ \\
\hline & Sometimes & (a) & 125 & 98 & 223 \\
\hline & & (b) & 47.9 & 42.1 & 45.1 \\
\hline & Rarely & (a) & 20 & 28 & 48 \\
\hline & & (b) & $7 \cdot 7$ & 12.0 & 9.7 \\
\hline & Never & (a) & 1 & 1 & 2 \\
\hline & & (b) & 0.4 & 0.4 & 0.4 \\
\hline & Total & (a) & 261 & 233 & 494 \\
\hline & & (b) & 100.0 & 100.0 & 100.0 \\
\hline
\end{tabular}

Continued in the next column

development, because it seeks to maintain the psychological capacity of the destination (Mowforth \& Munt, 2003) and because satisfied and happy residents may become an important destinations attribute for tourism marketing (Pyke et al., 2016). It is widely ac- 
Table 10 Continued from the previous column

\begin{tabular}{|c|c|c|c|c|c|}
\hline \multirow[t]{2}{*}{ Emotion } & \multirow[t]{2}{*}{ Item } & & \multicolumn{2}{|c|}{ TALC } & \multirow[t]{2}{*}{ Total } \\
\hline & & & Low & High & \\
\hline \multirow[t]{10}{*}{ Fear } & Often & (a) & 33 & 18 & 51 \\
\hline & & (b) & 12.7 & 7.8 & 10.4 \\
\hline & Sometimes & (a) & 81 & 73 & 154 \\
\hline & & (b) & 31.2 & 31.6 & 31.4 \\
\hline & Rarely & (a) & 122 & 102 & 224 \\
\hline & & (b) & 46.9 & 44.2 & 45.6 \\
\hline & Never & (a) & 24 & 38 & 62 \\
\hline & & (b) & 9.2 & 16.5 & 12.6 \\
\hline & Total & (a) & 260 & 231 & 491 \\
\hline & & (b) & 100.0 & 100.0 & 100.0 \\
\hline \multirow[t]{10}{*}{ Worry } & Often & (a) & 41 & 31 & 72 \\
\hline & & (b) & 16.0 & 13.4 & 14.8 \\
\hline & Sometimes & (a) & 112 & 116 & 228 \\
\hline & & (b) & 43.6 & 50.2 & 46.7 \\
\hline & Rarely & (a) & 92 & 77 & 169 \\
\hline & & (b) & 35.8 & $33 \cdot 3$ & 34.6 \\
\hline & Never & (a) & 12 & 7 & 19 \\
\hline & & (b) & $4 \cdot 7$ & 3.0 & 3.9 \\
\hline & Total & (a) & 257 & 231 & 488 \\
\hline & & (b) & 100.0 & 100.0 & 100.0 \\
\hline \multirow[t]{10}{*}{ Sadness } & Often & (a) & 19 & 7 & 26 \\
\hline & & (b) & $7 \cdot 4$ & 3.0 & $5 \cdot 3$ \\
\hline & Sometimes & (a) & 80 & 69 & 149 \\
\hline & & (b) & 31.0 & 29.7 & 30.4 \\
\hline & Rarely & (a) & 117 & 116 & 233 \\
\hline & & (b) & $45 \cdot 3$ & 50.0 & 47.6 \\
\hline & Never & (a) & 42 & 40 & 82 \\
\hline & & (b) & 16.3 & 17.2 & 16.7 \\
\hline & Total & (a) & 258 & 232 & 490 \\
\hline & & (b) & 100.0 & 100.0 & 100.0 \\
\hline
\end{tabular}

Notes (a) Count, (b) percentage within TALC.

cepted that vacations add to one's quality of life but links between tourism development and hosts' satisfaction with life remains unclear. The present study aims at adding empirical evidence about the links be-
Table 11 Association between Emotional Wellbeing, Level of Tourism Development and Interaction with Tourists

\begin{tabular}{|c|c|c|c|c|c|}
\hline & $R^{2}$ & $F$ & Sig. & (1) & (2) \\
\hline Calmness & 0.018 & 1.556 & 0.201 & $\begin{array}{l}-0.033 \\
(0.694)\end{array}$ & $\begin{array}{c}0.0120 .157 \\
(0.883)(0.059)\end{array}$ \\
\hline Contentment & 0.011 & 0.875 & 0.455 & $\begin{array}{c}0.134 \\
(0.108)\end{array}$ & $\begin{array}{c}0.050-0.058 \\
(0.536)(0.484)\end{array}$ \\
\hline Enjoyment & 0.022 & 1.854 & 0.138 & $\begin{array}{c}0.143 \\
(0.087)\end{array}$ & $\begin{array}{c}0.147-0.062 \\
(0.074)(0.460)\end{array}$ \\
\hline Fear & 0.008 & 0.630 & 0.596 & $\begin{array}{c}0.079 \\
(0.348)\end{array}$ & $\begin{array}{c}0.053-0.076 \\
(0.517)(0.369)\end{array}$ \\
\hline Worry & 0.017 & 1.378 & 0.250 & $\begin{array}{c}0.059 \\
(0.478)\end{array}$ & $\begin{array}{c}0.000-0.155 \\
(0.997)(0.067)\end{array}$ \\
\hline Sadness & 0.003 & 0.258 & 0.855 & $\begin{array}{c}0.000 \\
(1.000)\end{array}$ & $\begin{array}{c}0.025-0.039 \\
(0.765)(0.641)\end{array}$ \\
\hline
\end{tabular}

Notes Column headings are as follows: (1) TALC $\beta$, (2) interaction with tourists, (3) working in tourism; $p$-vales in parenthesis.

Table 12 Overall Regression Model for Satisfaction with Life

\begin{tabular}{lrrrrr}
\hline Item & $B$ & $\mathrm{SE}$ & $\beta$ & $t$ & Sig. \\
\hline (Constant) & -1.138 & 0.583 & -1.953 & 0.052 \\
TALC & 0.092 & 0.133 & 0.054 & 0.689 & 0.491 \\
Working in tourism & -0.003 & 0.133 & -0.002 & -0.021 & 0.983 \\
Interac. with tourists & -0.001 & 0.002 & -0.040 & -0.499 & 0.619 \\
Calmness & 0.037 & 0.089 & 0.029 & 0.419 & 0.676 \\
Contentment & -0.258 & 0.118 & -0.174 & -2.184 & 0.030 \\
Enjoyment & -0.235 & 0.100 & -0.181 & -2.364 & 0.019 \\
Fear & 0.105 & 0.080 & 0.099 & 1.315 & 0.190 \\
Worry & 0.153 & 0.092 & 0.128 & 1.654 & 0.100 \\
Sadness & 0.011 & 0.080 & 0.009 & 0.132 & 0.895 \\
Gender & 0.131 & 0.115 & 0.070 & 1.139 & 0.256 \\
Age & 0.005 & 0.005 & 0.054 & 0.903 & 0.367 \\
Highest educ. level & 0.327 & 0.082 & 0.247 & 3.966 & 0.000 \\
\hline
\end{tabular}

Notes Dependent variable: Satisfaction with life (factor).

tween tourism and residents' emotional wellbeing and satisfaction with life. Following the theoretical background and previous empirical research, four research hypotheses were tested. First, we hypothesized that 
the level of tourism development predicts residents' perceived level of satisfaction with life. The analysis section does not allow accepting this hypothesis because no significant association was identified between self-reported satisfaction with life and the level of tourism development. This study empirically assessed the satisfaction with six different aspects of life at destinations with different levels of tourism development. The city with high TALC is actually a rather small coastal city where locals can hardly avoid interaction with tourists. On the other hand, cities with low TALC are larger in area and have a substantially lower population (tourists and locals) per square meter; hence, it is hard to detect crowds, and tourists in particular, as well as tourism infrastructure and experiences. This finding challenges the prevailing assumption that higher levels of tourism by default lead to lower satisfaction with life of local residents and their low emotional wellbeing. Given that it is the interaction with tourists which may play a higher role in life satisfaction rather than the level of tourism development, we tested how interaction with tourists, at the subjective and objective level, predicts life satisfaction. Again, this study finds no statistically significant association between the two. The finding that no significant association exists between employment in tourism and satisfaction with life is extremely interesting. Employment in tourism brings at least economic benefits, hence some link to satisfaction with life should exist; especially given that residents working in tourism are more likely in support of tourism than those not working in this industry (McGehee \& Andereck, 2004). Nevertheless, it may be that results are very context dependent and that other factors (for example, emotions, family cycle) cause the gap between levels of tourism development and satisfaction with life, which would call for more research into the two concepts.

Secondly, we hypothesize (using separate hypotheses) that residents' emotional wellbeing depends on the level of tourism development and residents' interaction with tourism. Both hypotheses must be rejected, as empirical results demonstrate no significant association between the concepts. The two hypotheses followed the premises (1) that working in tourism is extremely demanding, which influences one's life satisfaction (Baum, 2007) and (2) higher level of interaction with tourists should affect (negatively) one's feeling of calmness or even fear (Peeters et al., 2018). The context in which the present study took place does not allow accepting this hypothesis, but the data also does not provide insights into why interaction with tourists does not affect any of the most typically experienced emotions. It is well accepted that a higher level of tourism development leads to less favourable residents' attitudes towards tourism (for example, Murphy, 1985; Teye et al., 2002); the present study demonstrates that the same logic does not hold for emotions or satisfaction with life.

Education, as a socio-demographic characteristic, and feelings of enjoyment and contentment as elements of emotional wellbeing are the only three significant predictors of residents' satisfaction with life. This finding challenges previous empirical insights about the negative impacts of tourism on local residents' satisfaction with life and emotional wellbeing. There exists the possibility that even in a context with a high level of tourism development, local residents may still have a chance to isolate themselves from tourism, thus preventing tourism from negatively impacting their everyday life. Empirical findings show that, irrespective of the perceived level of interaction with tourists, residents report similar levels of satisfaction with life. Interaction with tourists was measured as a subjective (perceived level of interaction) and objective (working in tourism industry) measurement, but results of this study show that neither significantly adds to nor reduces the level of life satisfaction.

Although emotions appear less frequently associated with tourism, they are the basis for expression of individuals and an important factor in creating satisfaction for both hosts and guests. A high level of satisfaction is the foundation for happiness, and because tourism is recognized as a means of generating happiness (Pearce et al., 2011) it is reasonable to interpret tourism as a tool for achieving happiness for tourists as well as residents. However, our study points out that the existing believed association of tourism and life satisfaction and emotional wellbeing cannot be generalized across different contexts or even cultures. 
Tourism success is measured beyond typical income and arrivals numbers, which echoes the principles of sustainable yield. By creating a welcoming atmosphere, locals contribute to a positive tourism experience but they only can do this if they themselves feel satisfied and happy. Quality of life has to be maintained, with special attention given to improvements, with a view to achieving mutual effect; quality of life of local residents and tourists. Interweaving good relationships, coherence and careful planning is the key to successful, healthy tourism development that complements the lives of locals. The empirical findings of this study are somewhat surprising, given that the emotional wellbeing and satisfaction were measured at destinations with extremely opposite levels of tourism development. Nevertheless, findings do reflect current understanding that achieving social sustainability is context dependent (Font \& McCabe, 2017) and that research is needed around quality of life and tourism (Liburd et al., 2012). We hope that the present study has shed more light on the aspects of social sustainability, as a concept involving residents' emotional wellbeing and satisfaction with life, and their dependence on different contexts.

Practically, this study contributes to the body of knowledge on managing residents' emotional wellbeing and satisfaction with life. We empirically highlight that feelings of contentment and enjoyment act as drivers of satisfaction with life, dependent on the level of tourism development. Destination organizations and tourism providers should monitor the levels of contentment and enjoyment as well as investigate which aspects of tourism lead to higher levels of the two emotions. In addition, when assuring high levels of contentment and enjoyment, these two emotions should be used as destination attributes marketed to the tourists. Marketing campaigns must demonstrate that locals are content and enjoy their lives at the destination. In addition, a high level of education appears as a significant driver of life satisfaction and emotional wellbeing. This implies that tourism organizations should work with educational institutions to help build knowledge about tourism impacts at the destination to improve positive emotions about tourism and, finally, higher perceived satisfaction with life.
More research into dimensions of life satisfaction, emotional wellbeing and tourist interaction is needed to guide destination management policies and operations in ensuring social sustainability of tourism. Empirical findings in this study come by surprise and actually call for more specific studies into the levels or thresholds of interaction with tourists and its impact on residents' life satisfaction and emotional wellbeing. This would empirically determine how many and which kind of interactions with tourists are manageable or tolerable for the local population without sacrificing their satisfaction with life. While dimensions of interaction with tourism are beyond the scope of the current study, we believe it may play an important role in emotional wellbeing and satisfaction with life. Hence, future research should look into different context-destination specific dimensions of interaction with tourists and its role in hosts' emotional wellbeing and satisfaction with life, most likely, using a mixed method approach, where a qualitative approach would identify different dimensions and a quantitative approach would test the relevance and potential generalizability across similar destinations. This would improve the managerial ability of destination management organizations to benefit from emotional wellbeing and satisfaction with life of the local population.

\section{References}

Allport, G. W. (1961). Pattern and growth in personality. Holt, Rinehart \& Winston.

Baum, T. (2007). Human resources in tourism: Still waiting for change. Tourism Management, 28(6), 1383-1399.

Belisle, F. J., \& Hoy, D. R. (1980). The perceived impact of tourism by residents a case study in Santa Marta, Colombia. Annals of Tourism Research, 7(1), 83-101.

Buckley, R. (2011). Tourism and environment. Annual Review of Environment and Resources, 36, 397-416.

Butler, R. W. (1980). The concept of the tourist area life-cycle of evolution: Implications for management of resources. Canadian Geographer, 24(1), 5-12.

Butler, R. W. (2006). The origins of the tourism area life cycle. In R. W. Butler (Ed.), The tourism area life cycle (vol. 1, pp. 13-26). Channel View Publications.

Cummins, R. A. (1993). The comprehensive quality of life scale intellectual disability (4th ed.). Deakin University School of Psychology.

Dolnicar, S., Grün, B., \& Leisch, F. (2011). Quick, simple and 
reliable: Forced binary survey questions. International Journal of Market Research, 53(2), 231-252.

Dolnicar, S., Yamanadram, V., \& Cliff, K. (2012). The contribution of vacation to quality of life. Annals of Tourism Research, 39(1), 59-83.

Doxey, G. (1975). A causation theory of visitor-resident irritants: Methodology and research inferences; The impact of tourism. In The Sixth Annual Conference Proceedings of the Travel Research Association (pp. 195-198). The Travel Research Association.

Font, X., \& McCabe, S. (2017). Sustainability and marketing in tourism. Journal of Sustainable Tourism, 25(7), 869883.

George, D., \& Mallery, P. (2003). sPss for Windows step by step: A simple guide and reference, 11.0 update (4th ed.). Allyn \& Bacon.

Gholipour, H. F., Tajaddini, R., \& Nguyen, J. (2016). Happiness and inbound tourism. Annals of Tourism Research, $57(\mathrm{c}), 251-253$.

Gnoth, J. (1997). Tourism motivation and expectation formation. Annals of Tourism Research, 24(2), 283-304.

Ho, G. K. S., \& McKercher, B. (2015). A review of life cycle models by plog \& butler from a marketing perspective. In M. Kozak \& N. Kozak (Eds.), Destination marketing: An international perspective (pp. 145-154). Routledge.

Kahneman, D., \& Deaton, A. (2010). High income improves evaluation of life but not emotional well-being. PNAS, $7(38), 16489-16493$.

Kim, K., Uysal, M., \& Sirgy, M. J. (2013). How does tourism in a community impact the quality of life of community residents? Tourism Management, 36, 527-540.

Kubickova, M., Croes, R., \& Rivera, M. (2017). Human agency shaping tourism competitiveness and quality of life in developing economies. Tourism Management Perspectives, 22, 120-131.

Lee, T. H. (2013). Influence analysis of community resident support for sustainable tourism development. Tourism Management, 34, 37-46.

Liang, Z. X., \& Hui, T. K. (2016). Residents' quality of life and attitudes toward tourism development in China. Tourism Management, 57(7), 56-67.

Liburd, J. J., Benckendorff, P., \& Carlsen, J. (2012). Tourism and quality-of-life: How does tourism measure up? In M. Uysal, R. R. Perdue, \& M. J. Sirgy (Eds.), Handbook of tourism and quality of life research (pp. 105-132). Springer.

Lin, Y., Kerstetter, D., Nawijn, J., \& Mitas, O. (2014). Changes in emotions and their interactions with personality in a vacation context. Tourism Management, 40, 416-424.
McGehee, N., \& Andereck K. 2004. Factors predicting rural resident's support of tourism. Journal of Travel Research, 43(2), 131-140.

Mohit, M. A. (2014). Present trends and future directions of quality-of-life. Procedia: Social and Behavioral Sciences, $153,655-665$.

Mowforth, M., \& Munt, I. (2003). Tourism and sustainability: Development and new tourism in the third world (2nd ed.). Routledge.

Murphy, P. (1985). Tourism: A community approach. Routledge.

Pearce, P. L., Filep, S., \& Ross, G. (2011). Tourists, tourism and the good life. Routledge.

Peeters, P., Gössling, S., Klijs, J., Milano, C., Novelli, M., Dijkmans, C., Eijgelaar, E., Hartman, S., Heslinga, J., Isaac, R., Mitas, O., Moretti, S., Nawijn, J., Papp, B., \& Postma, A. (2018). Research for TRAN Committee-Overtourism: Impact and possible policy responses. European Parliament.

Perdue, R. R., Long, P. T., \& Allen, L. (1990). Resident support for tourism development. Annals of Tourism Research, 17(4), 586-599.

Pizam, A. (1978). Tourism's impacts: The social costs to the destination community as perceived by its residents. Journal of Travel Research, 16(4), 8-12.

Pratt, S., McCabe, S., \& Movono, A. (2016). Gross happiness of a 'tourism' village in Fiji. Journal of Destination Marketing and Management, 5(1), 26-35.

Prayag, G., Hosany, S., Nunkoo, R., \& Alders, T. (2013). London residents' support for the 2012 Olympic Games: The mediating effect of overall attitude. Tourism Management, 36(c), 629-640.

Pyke, S., Hartwell, H., Blake, A., \& Hemingway, A. (2016). Exploring well-being as a tourism product resource. Tourism Management, 55, 94-105.

Ribeiro, M. A., Pinto, P., Silva, J. A., \& Woosnam, K. M. (2017). Residents' attitudes and the adoption of protourism behaviours: The case of developing island countries. Tourism Management, 61, 523-537.

Rivera, M., Croes, R., \& Lee, S. H. (2016). Tourism development and happiness: A residents' perspective. Journal of Destination Marketing and Management, 5(1), 5-15.

Sharpley, R. (2014). Host perceptions of tourism: A review of the research. Tourism Management, 42, 37-49.

Sirgy, M. J., \&, Lee, D. J. (2006). Macro measures of consumer well-being: A critical analysis and research agenda. Journal of Macromarketing, 26(1), 27-44.

Stylidis, D., Biran, A., Sit, J., \& Szivas, E. M. (2014). Residents' support for tourism development: The role of 
residents' place image and perceived tourism impacts. Tourism Management, 45, 260-274.

Teye, V., Sonmez, S. F., \& Sirakaya, E. (2002). Residents' attitudes toward tourism development. Annals of Tourism Research, 29(3), 668-688.

Uran Maravić, M., \& Juvan, E. (2009). Strategije v turizmu: oblikovanje strategije turizma in vloga deležnikov. Društvo za akademske in aplikativne raziskave.

Uysal, M., Woo, E., \& Singal, M. (2012). The tourist area life cycle (TALC) and its effect on the quality-of-life (QOL) of destination community. In M. Uysal \& R. R. Perdue (Eds.), Handbook of tourism and quality-of-life research: Enhancing the lives (pp. 423-443). Springer.
Uysal, M., Sirgy, M. J., Woo, E., \& Kim, H. L. (2016). Quality of life (QOL) and well-being research in tourism. Tourism Management, 53, 244-261.

Williams, T. A. (1979). Impact of domestic tourism on holt population: The evolution of a model. Tourism Recreation Research, 4(2), 15-21.

World Tourism Organization. (2017). UNWTO tourism highlights: 2017 edition [Brochure].

World Tourism Organization. (2019). International tourism highlights: 2019 edition [Brochure]. 